\title{
Simulation Research on Hydraulic Support Based Virtual Prototyping
}

\author{
Yuekan Zhang \\ College of Mechanical and Electronic \\ Engineering \\ Shandong University of Science and \\ Technology \\ Qingdao, China \\ zhangyk2007@163.com \\ Peikun Liu \\ College of Mechanical and Electronic \\ Engineering \\ Shandong University of Science and \\ Technology \\ Qingdao, China \\ lpk710128@163.com
}

\author{
Jingzhen Cao \\ College of Mechanical and Electronic \\ Engineering \\ Shandong University of Science and \\ Technology \\ Qingdao, China \\ 18865735489@163.com \\ Xiahui Gui \\ Chinese National Engineering \\ Research Center of Coal Preparation \\ and Purification \\ China University of Mining and \\ Technology name of organization \\ Xuzhou,China \\ guixiahui1985@163.com
}

\author{
Lanyue Jiang \\ College of Mechanical and Electronic \\ Engineering \\ Shandong University of Science and \\ Technology \\ Qingdao, China \\ jianglanyue5@163.com \\ Junru Yang \\ College of Mechanical and Electronic \\ Engineering \\ Shandong University of Science and \\ Technology \\ Qingdao, China \\ jryangzhang@163.com
}

\begin{abstract}
To overcome limitations of current designs of hydraulic supports based on conventional physical prototype, we propose a virtual prototyping based design mode for hydraulic supports. In this study, a 3D numerical model of hydraulic support was established by numerical simulations and stress distributions on hydraulic support were investigated. Also, motion simulation and interference detection of the working process of hydraulic supports were involved. The results indicated that the proposed hydraulic support based virtual prototyping is viable and the simulation results are consistent with practical working conditions of hydraulic supports. Indeed, virtual prototyping can improve the design method and reduce the design period. This study facilitates optimized design of hydraulic supports, thus providing references for industrial applications.
\end{abstract}

\section{Keywords—virtual prototype, hydraulic support, simulation}

\section{INTRODUCTION}

As a key equipment for work safety in coal mining, hydraulic support is usually working under complicated geological conditions and in harsh environment. Owing to the high cost of hydraulic supports $(100,000$ to $1,000,000$ RMB), a physical prototype of hydraulic support for tests is quite challenging and the tests are usually destructive. Additionally, detections of failure cause and fault points in practical tests are usually extremely difficult due to the sophisticated structure and interactive components. Therefore, the physical prototype based mode severely limits improvements of hydraulic support design. With virtual prototyping, the design concepts and structural components can be dynamically visualized. In this way, any single component can be modified easily. Additionally, kinematic and dynamic characteristics of hydraulic supports can be evaluated by virtual simulations so that problems can be identified and the product design can be optimized. Currently, virtual prototyping based designs for hydraulic supports have been intensively studied. References [1-4] proposed 3D entity modeling of hydraulic supports using 3D mechanical design software and defects in the design can be visualized and easily handled. References [5-17] reported finite element analysis of bearing characteristics of key components in hydraulic support using 3D numerical modelling and proposed optimization of structural design. References [1821] established a kinematic model of hydraulic supports and reported kinematic and dynamic simulations of hydraulic supports, followed by design optimization. Additionally, a virtual prototype analysis platform was established for virtual prototypes using SolidWorks. Kinematics of components in the hydraulic support system were obtained by motion simulation and dynamic interference detection [22-24].

In summary, owing to sophisticated structures of hydraulic supports, most studies involving structure simplification in 3D modeling and precise 3D modeling of hydraulic supports are widely absent. Meanwhile, strength analyses were applied for key structural components only and few studies involved entire frame finite element simulations of hydraulic supports. Therefore, this study proposes precise 3D modeling of hydraulic supports and entire frame force analysis and motion simulation of hydraulic supports to investigate their stress distribution and motion, thus providing references for design optimization of hydraulic supports.

\section{3D MODELLING OF HYDRAULIC SUPPORT}

\section{A. 3D modelling of components}

The model was established using software (Pro/E). Figs. $1,2,3,4,5$, and 6 shows the models of base, head beam, shield beam, front and back connecting rods, column, and lifting jack of the hydraulic support, respectively. 


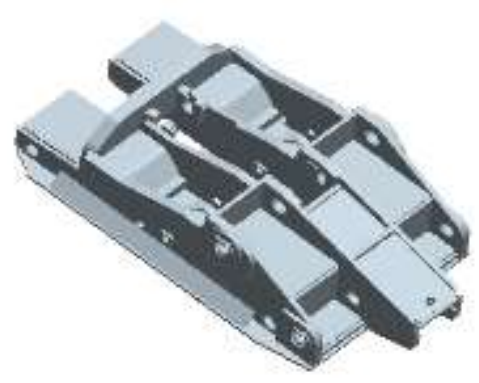

Fig.1 The base

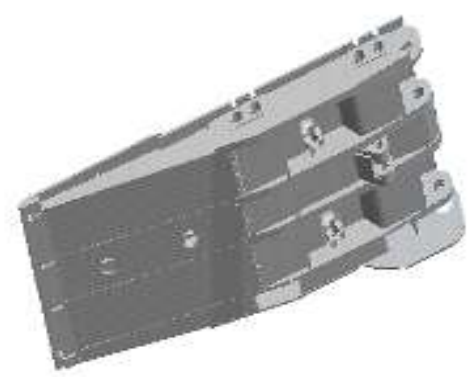

Fig.2 The head beam

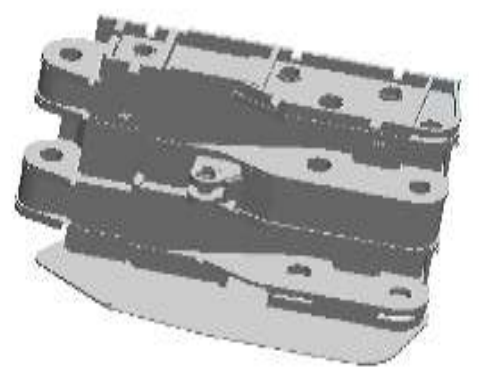

Fig.3 The shield beam
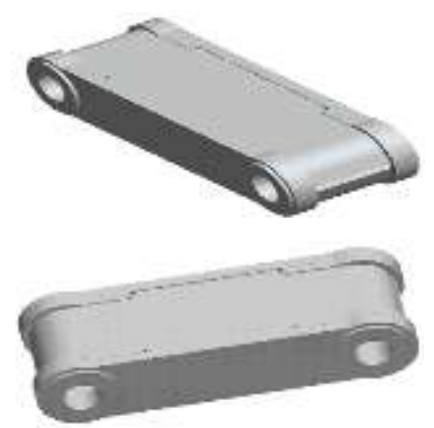

Fig.4 The front and back connecting rods

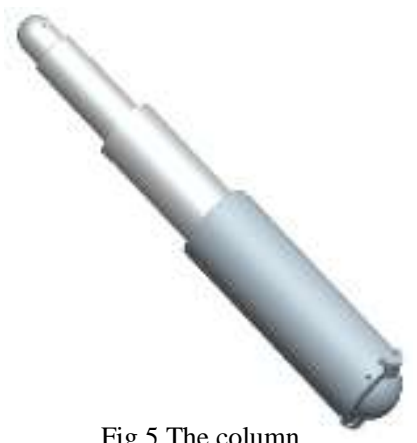

Fig.5 The column

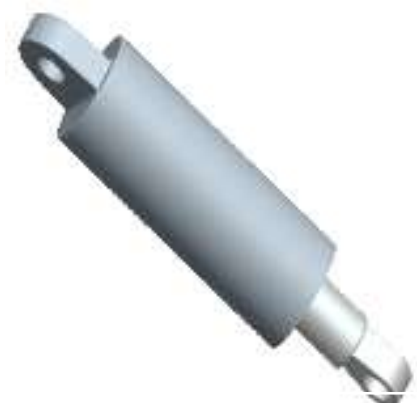

Fig.6 The lifting jack

\section{B. Virtual prototyping based hydraulic support}

Upon design of individual components, assembly of these components can be achieved accordingly. The assembly of components is indeed position constraints of these components. The assembly model of hydraulic support is regarded as a system of consisting of several sub-assemblies, including base, pre and post connecting rods, shield beam, head beam. The Pro/E allows three constraints, including "place", "move", and "connect". To allow motions of assembled components, "connect" was applied for support assembly in this study. Fig.7 shows entity model of assembled hydraulic supports.

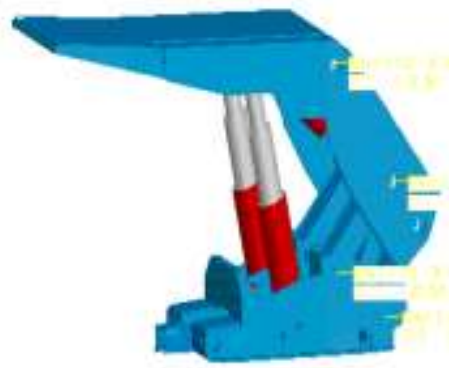

Fig.7 3D model of the hydraulic support

\section{FINITE ELEMENT ANALYSIS OF HYDRAULIC SUPPORT}

\section{A. Boundary Conditions}

During mining processes, the supports experience both supportive forces by columns and pressures by wall rocks in the work face. For tests, forces by wall rocks on underground support were reflected by applying different bearers. If the force on support by bearer is regarded as an external load, the hydraulic support is a hyper-static system and the force on support by bearer cannot be calculated using force equilibrium equation. Therefore, the force by bearer is regarded as part of boundary conditions instead of an external load.

\section{B. Load Determination}

As the bearer is regarded as part of the boundary conditions, the external loads are loads on the head beam by the two columns. Herein, the resistance to hydraulic support was $31.5 \mathrm{Mpa}$ and the supportive force by each column was $15.75 \mathrm{Mpa}$. With safety factor of 1.2 , the load on head beam was $15.75 \times 1.2=20 \mathrm{MPa}$. Among all working conditions of hydraulic support, load concentration on head beam end points, eccentric loading on beam, head beam torsion, base torsion, and load concentration on base end points should be particularly investigated. This study involves simulations of hydraulic supports under these working conditions. 


\section{Strength Analysis of Load Concentration on Head Beam End Points}

Selecting SOLID 95 and free gridding led to 75259 units and 127827 nodes, as shown in Fig. 8. The bearer was regarded as a constraint and the loading location is as shown in Fig. 9. As shown in Fig. 10 and Fig.11, the maximum displacement was $6.068 \mathrm{~mm}$ and the maximum stress was 467.418 MPa. Meanwhile, stress concentrations on bearer are significant, which is consistent with actual working conditions.

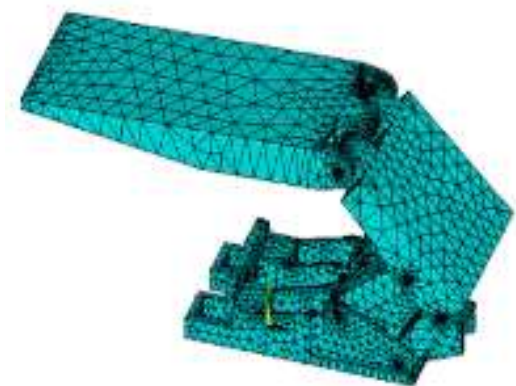

Fig. 8 The meshing of the hydraulic support

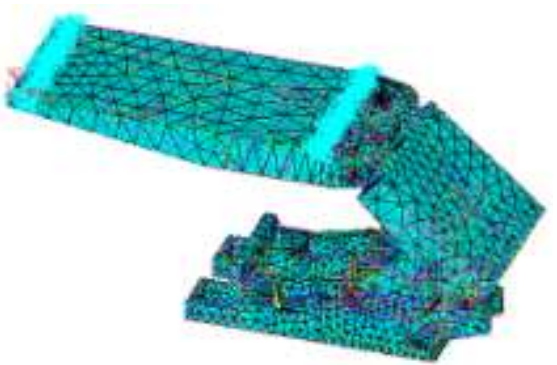

Fig.9 The loading position of two side of top beam

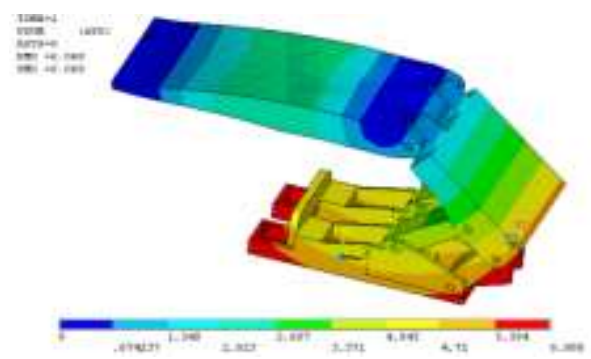

Fig.10 The displacement of the top beam

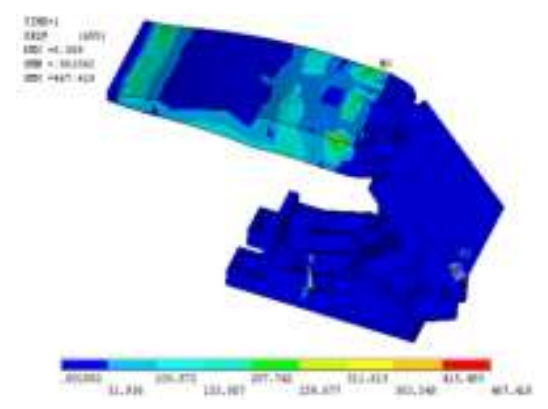

Fig.11 The stress of the top beam

\section{Strength Analysis of Head Beam Torsion}

The bearer was regarded as a constraint and its location is as shown in Fig. 12.

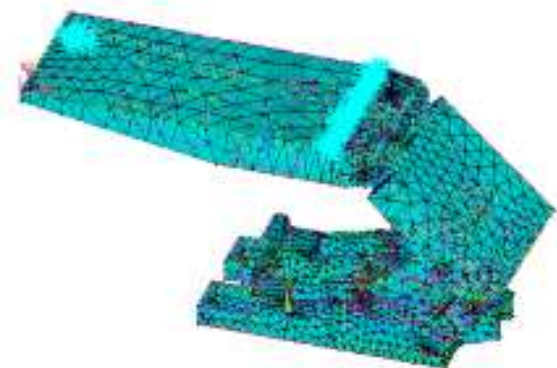

Fig.12 The position of the stepping-block

The DOFs of base bottom node in $\mathrm{Y}$ direction and the presser contacting with the head beam in $\mathrm{X}, \mathrm{Y}$, and $\mathrm{Z}$ directions along the axis were constrained, as shown in Fig. 13. Applying plane loads and the results obtained are as shown in Fig. 14 and Fig.15.

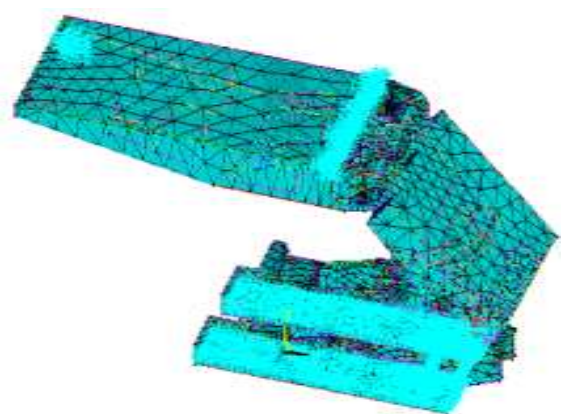

Fig.13 The loading restriction

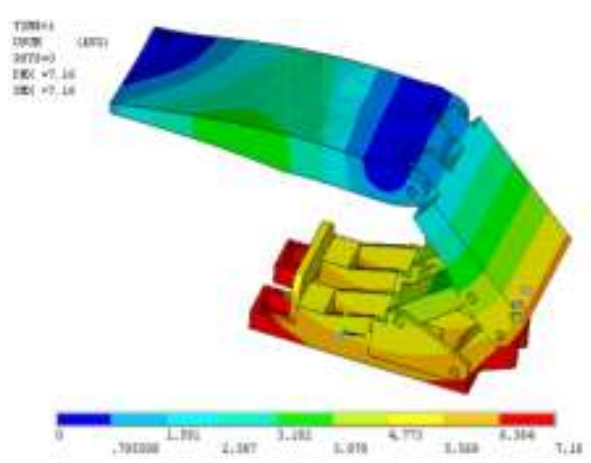

Fig.14 The torsion displacement of the top 1......

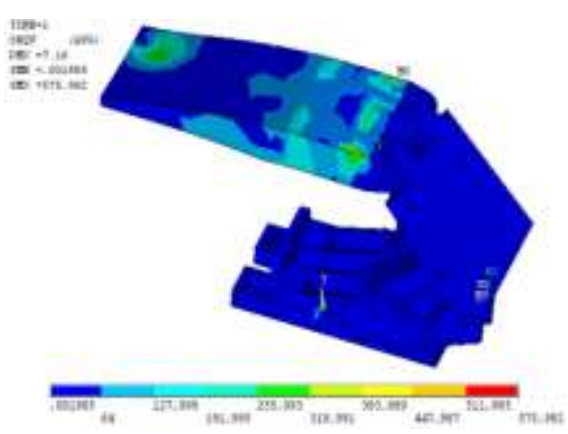

Fig. 15 The torsion stress of the top beam

According to the displacement cloud chart, the maximum displacement in the presence of torsion loads on head beam was $7.16 \mathrm{~mm}$. According to the stress cloud chart, the 
maximum stress was $575.982 \mathrm{MPa}$ and it appeared at the connection point of bearer and the head beam. Meanwhile, most severe stress concentrations were observed at the constraint bearer.

\section{E. Strength Analysis of Load Concentrations on Base End Points}

As shown in Fig. 16, the bearer was regarded as a constraint. The displacement cloud chart (Fig. 17), the geometric shapes before and after deformations (Fig. 18), and the stress cloud chart (Fig. 19) were obtained by finite element analysis. As observed, the maximum stress was 382.342 MPa.

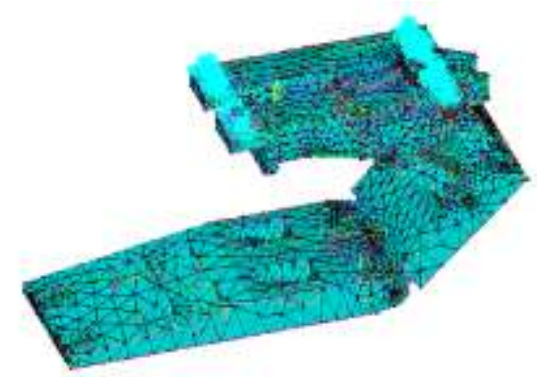

Fig.16 The position of stepping-block of the base

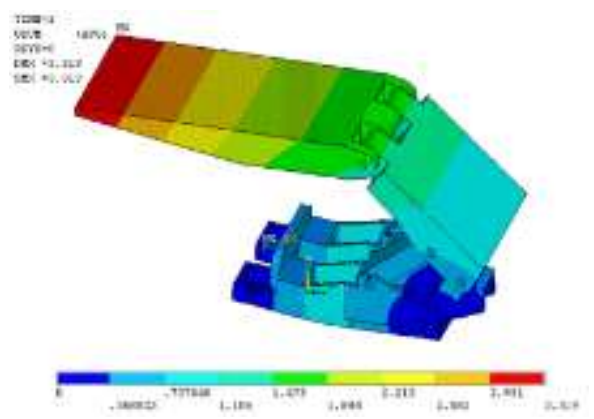

Fig.17 The displacement of concentrated loading of the base

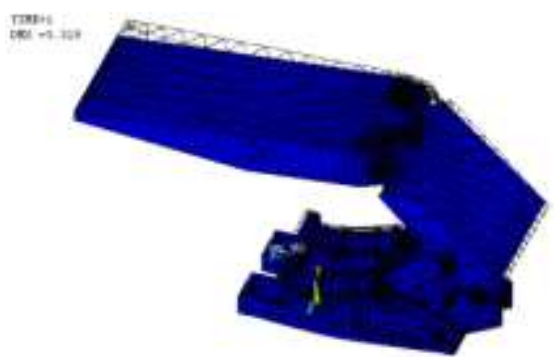

Fig.18 The deformed nephogram of concentrated loading of the base

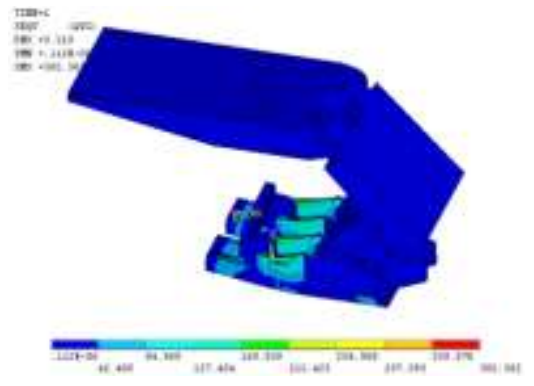

Fig.19 The stress of concentrated loading of the base

\section{F. Strength Analysis of Base Torsion}

Applying vertical constraints on the bearer and free gridding led to 85672 units and 143468 nodes, as shown in Fig. 20. By applying loads along the axial direction of the column, base torsion deformations (Fig. 21), torsion displacement cloud chart (Fig. 22), and stress cloud chart (Fig. 23) were obtained by analysis using the ANSYS software. As observed, the maximum displacement and stress of the support in the presence of base torsion loads were $5.004 \mathrm{~mm}$ and $648.723 \mathrm{MPa}$, respectively. The maximum stress observed was significantly higher than those in other cases mentioned above but is within the yield strength of the material.

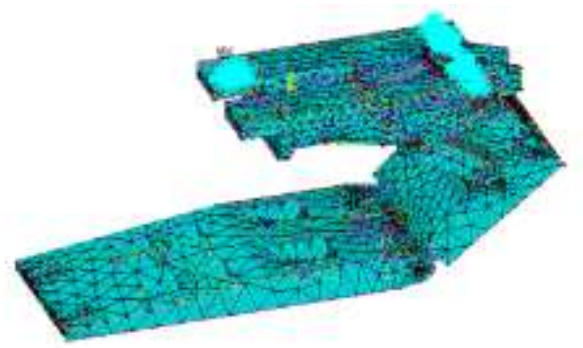

Fig.20 The position of the stepping-block of torsion loading of the base

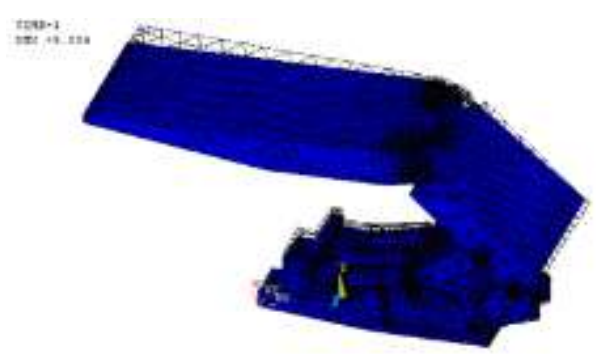

Fig.21 The deformed nephogram of torsion loading of the base 


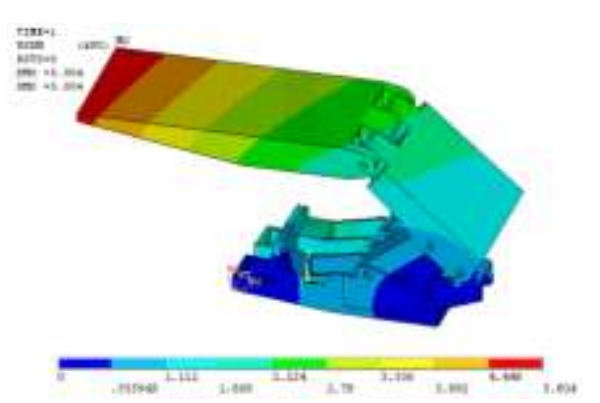

Fig.22 The displacement of torsion loading of the base

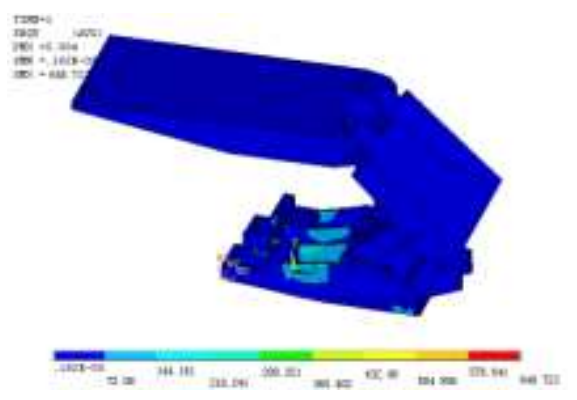

Fig.23 The stress of torsion loading of the base

\section{G. Strength Analysis of Eccentric Loading on Beam}

Fig. 24 shows the location of bearer in case of eccentric loading on beam. Free gridding of support led to 75135 units and 107464 nodes, as shown in Fig. 25. By applying loads along the axial direction of the column, cloud charts of displacements (Fig. 26) and stresses (Fig. 27) of the support in case of eccentric loading on beam were obtained by analysis using the ANSYS software. As observed, the maximum displacement and stress of the support in case of eccentric loading on beam were $4.176 \mathrm{~mm}$ and $672.886 \mathrm{MPa}$, respectively. Hence, eccentric loading on beam is one of the working conditions involving largest external loads and most severe stress concentrations.

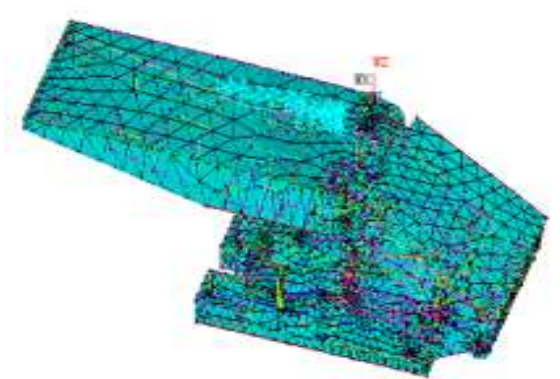

Fig.24 The stepping-block position of one side of the top beam

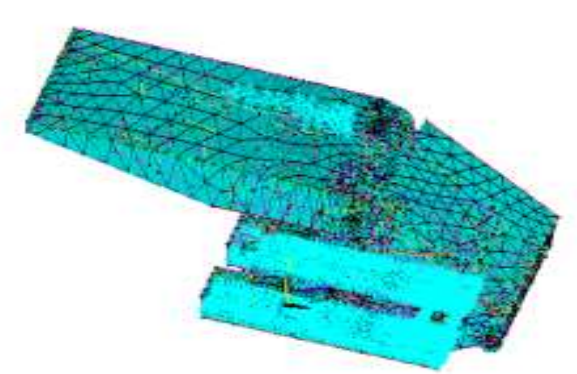

Fig.25 The one side loading restriction top of the beam

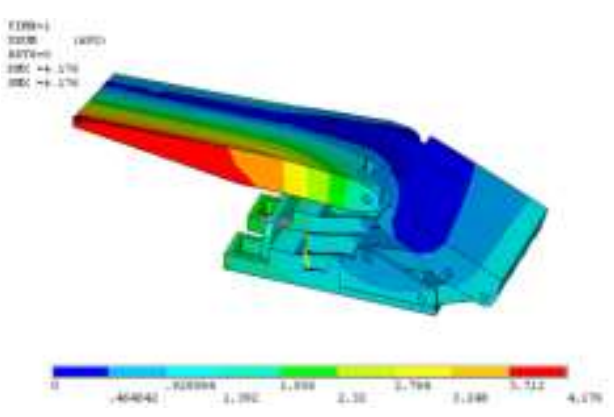

Fig.26 The displacement of one side loading of the top beam

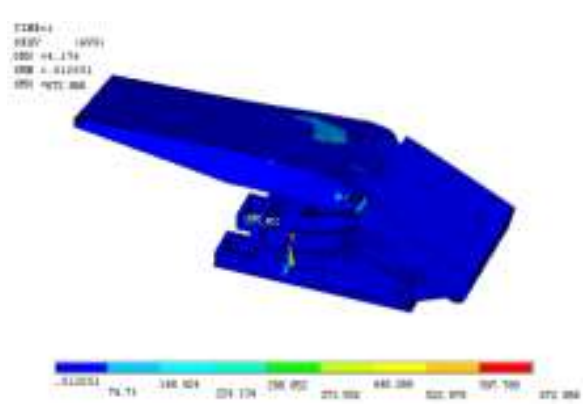

Fig. 27 The stress of one side loading of the top beam

\section{MOTION SIMULATION OF HYDRAULIC SUPPORT}

\section{A. Establishment of Motion Model of Hydraulic} Support

The motion model of hydraulic support was established (see Fig. 28) by 3D assembly modeling of its components involving motion pair and driver.

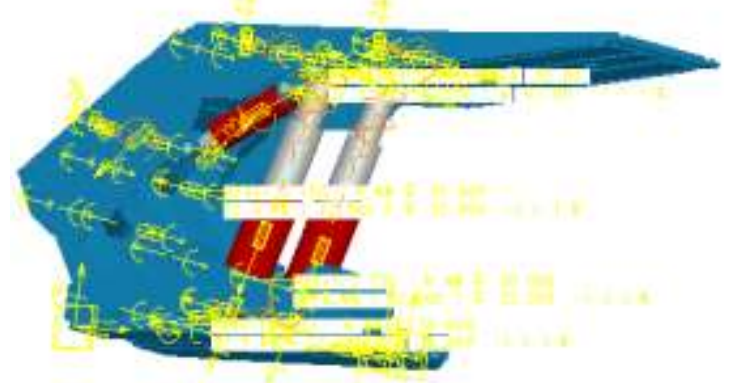

Fig.28 The movement assemble model of hydraulic support 


\section{B. Motion Simulation of Hydraulic Support}

Once entering the Mechanism module, drivers are established and their motion orders are adjusted so that different parts have individual drivers to achieve motion of the entire system. Fig. 29 shows the motion simulation process of elevation of hydraulic support head beam and it allows intuitive understanding of dynamic characteristics of the system. The results indicated good rationality of hydraulic support structures and absence of motion interferences.
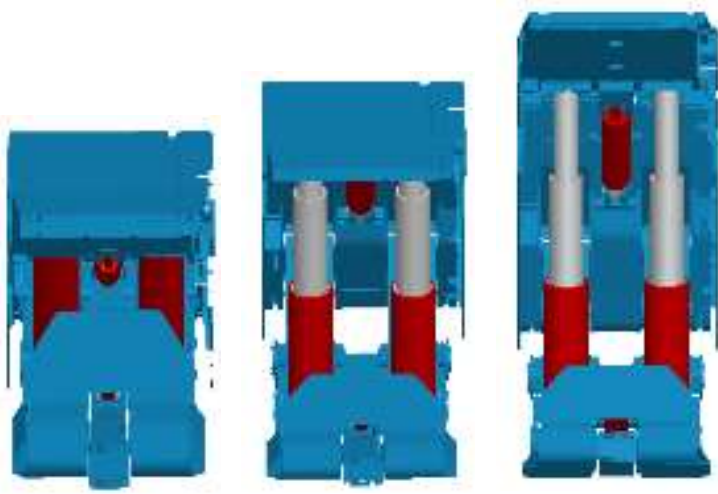

Fig.29 The risen process of hydraulic support

The elevating structure of the proposed hydraulic support is a four-link structure consisting of shield beam, pre and post connecting rods, and base. For the design of the fourlink structure, the variation of end face distance shall be minimized during the elevation of supports within the working range so that the head beam can protect the roof. Fig. 30 shows end point displacements of hydraulic support head beam obtained by motion simulations. Fig. 31 shows end point displacements of head beam vs. time. As observed, the maximum horizontal displacement of end point of support head beam was $94 \mathrm{~mm}(2358-2264 \mathrm{~mm})$, which was below $100 \mathrm{~mm}$ (the maximum horizontal displacement allowed), indicating good rationality of the four-link structure of hydraulic support in terms of size and other design requirements.

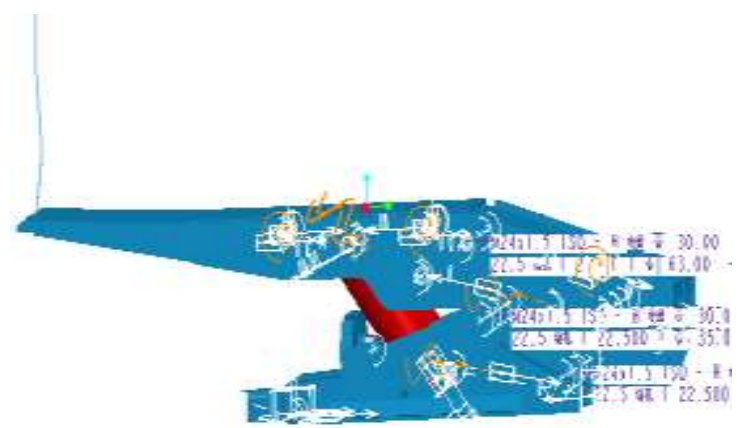

Fig.30 The double twist curve of the top beam's end

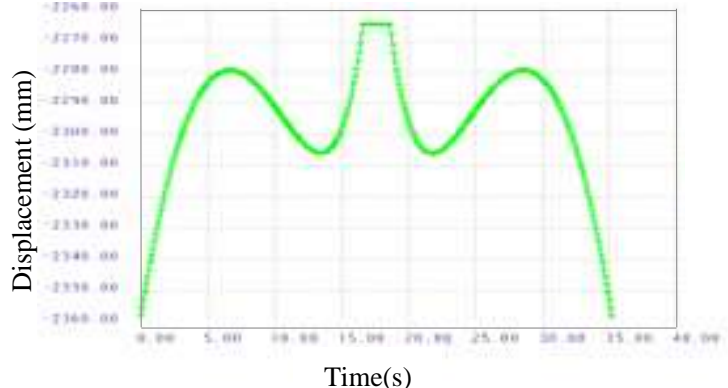

Fig.31 The displacement-time curve of the top beam's

\section{CONCLUSIONS}

To overcome limitations of current designs of hydraulic supports, a 3D numerical model was established for hydraulic supports by introducing virtual prototyping and static simulation and motion simulations of harsh environments in which hydraulic supports works were involved. The following conclusions can be drawn:

The locations of peril points and stress distribution in hydraulic supports were obtained and used for optimization of hydraulic support design.

Systematic motion simulations of hydraulic supports were involved and the results indicated absence of motion interferences and rationality of the four-link design of hydraulic supports.

The proposed virtual prototyping based hydraulic support is viable Indeed, virtual prototyping can improve the design method and reduce the design period. This study provides references for industrial applications.

\section{ACKNOWLEDGMENT}

In this paper, the research was sponsored by the Natural Science Foundation of Shandong province, China (No. ZR2016EEM37), Key national research and development programs, China(No.2018YFC0604702)and key research and development project of Shangdong province, China (No. 2017GSF216004).

\section{REFERENCES}

[1] Wang Guofa, Xu Yajun and Sun Shoushan, "3D modeling of hydraulic powered support and dynamic simulation," Coal Science and Technology, vol. 31(1), pp. 24-45, 2013.

[2] Liu Hongyu and Fan Xun. "Applying solidworks software to improve the design capability for hydraulic support," Coal Mine Machinery, vol. (5),pp. 65-66, 2005

[3] Ning Guifeng and Man Cuihua.Research on the applications of CAE on hydraulic power support," Coal Mine Machinery, vol. (2),pp. 4951, 2005.

[4] Xu Yajun, Wang Guofa and Cai BingYuan, "Study on Virtual Prototype Technology in Hydraulic Powered Support”.Coal Mining Technology, vol. 8(4), pp. 8-11, 2003.

[5] He Wenbin, Yao Hengyang and Ma Jun, "Strength finite element analysis of full frame of transition hydraulic support," Coal Technology, vol. 36(10), pp. 223-225, 2017.

[6] Wan Lirong, KongShuai and Meng Zhaosheng, "Finite element analysis of whole thin coal hydraulic support basedon workbench," Coal Technology, vol. 34(4), pp. 209-212, 2017.

[7] Wei Dongliang. "Hydraulic Support Digital and Visual Design," Coal Mine Machinery, vol. 38(4), pp. 4-5, 2017.

[8] Dong Jianrong and Zhang Xin. "Study On The Design Method Of The Reliablity Optimization Of The Powered Support Cover Beam," China Mining Magazine, vol. 26(6), pp. 161-165, 2017. 
[9] Yu Di,Chen Xinzhong and Huang Yongzhi."Finite Element Analysis of Key Components of QY200/14/31 Powered Support," Coal Mining Tchnology, vol. 16(3), pp. 107-110, 2011.

[10] Li Zhongwen and Hao Chunfen. "Design and Finite Element Analysis of Hydraulic Roof Support ZFY4800/16/30," Coal Mine Machinery, vol. 37(12), pp. 9-11, 2016.

[11] Niu Qingna,Yang Lijie and Yin Dongchen. "Optimized Design on Four Linking Bar Mechanism of HydraulicSupport Based on ADAMS," Coal Mine Machinery, vol. 38(3), pp. 156-157, 2017.

[12] Yan Zhiqin and Liu Yanping. "Analysis of Caving Coal Hydraulic Support Finite Element SimulationBased on ANSYS," Coal Technology, vol. 35(8), pp. 265-266, 2016.

[13] Zhou Yijun,Dong Ying and Yu Xianghong. "Analysis of Roof Beam of Hydraulic Support for Top Coal CavingMining Based on Simulation with ANSYS," Journal of Anhui University of Science and Technology( Natural Science), vol. 32(3), pp. 25-28, 2012.

[14] Ma Duanzhi and Wang Enpeng. "Development of Two-legs Shield Powerful Caving Coal Hydraulic Support for Large Mining Height Face," Coal Science and Technology, vol. 41(8), pp. 84-91, 2013.

[15] Xu Yajun. "Theoretical Study and Application on External Load Function Location of Canopy in Hydraulic Powered Support[J].Coal Science and Technology, vol. 43(7), pp. 102-106, 2015.

[16] Hu Denggao and Fan Xun. "Reliability and Sensitivity Analysis of Hydraulic Support," Journal of Liaoning Technical University (Natural Science), vol. 35(6), pp. 636-641, 2016.
[17] Lv Kaibo, Chang Hao and Xing Manxi, "Study on Dynamic Simulation of Experimental Tests for Powered Supports," Coal Technology, vol. 35(8), pp. 219-221, 2016.

[18] Wang Jicai. "Simulation of Coal Mine Virtual Hydraulic Support Based on VirtualReality Technology," Coal Technology, vol. 36(10), pp. 259-261, 2017.

[19] Si Yanfei,Wang Shouxin and Li Liang. "Kinematic Simulation and Optimal Design of Hydraulic Support Based on Solidworks," Coal Mine Electromechanical, vol. 4(2), pp. 10-12, 2014.

[20] Zhan Xiangde. "Optimized Design of Hydraulic Support Based on SolidWorks," Coal Technology, vol. 35(9), pp. 271-273, 2016.

[21] Cai Wenshu. "Rigid-Flexible Multi-Body Dynamics Simulation ofHydraulic Support Based on Finite Element Analysis," Coal Mine Electromechanical, vol. (2), pp. 11-14, 2017.

[22] Xu Yajun,Cui Liu and Zhu Jun. "Movement Simulation and Dynamic Interference Detection of Powered Support Based on Virtual Prototyping Technology," Coal Mine Electromechanical, vol. (12), pp. 67-69, 2014.

[23] Gao Yu, Shi Lan and Zhao Shuqing. "The Virtual Prototype Modeling and Analysis of Hydrulic Shield," Journal of Taiyuan University Of Technology, vol. 36(3), pp. 434-436, 2005.

[24] $\mathrm{Xu}$ Yajun and Wang Guofa. "Interference detection of powered support model based on virtual prototyping," Coal Technology, vol. 35(9), pp. 34-36, 2016. 